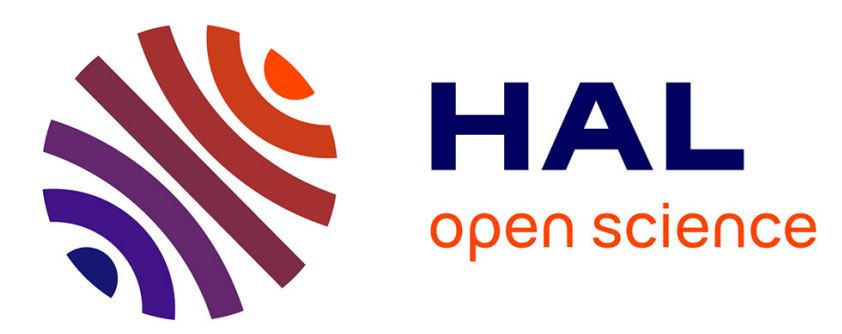

\title{
Is PCBs concentration variability between and within freshwater fish species explained by their contamination pathways?
}

\author{
C. Lopes, M.E. Perga, A. Peretti, M.C. Roger, H. Persat, M. Babut
}

\section{> To cite this version:}

C. Lopes, M.E. Perga, A. Peretti, M.C. Roger, H. Persat, et al.. Is PCBs concentration variability between and within freshwater fish species explained by their contamination pathways?. Chemosphere, 2011, 85 (3), p. 502 - p. 508. 10.1016/j.chemosphere.2011.08.011 . hal-00648443

\section{HAL Id: hal-00648443 \\ https://hal.science/hal-00648443}

Submitted on 5 Dec 2011

HAL is a multi-disciplinary open access archive for the deposit and dissemination of scientific research documents, whether they are published or not. The documents may come from teaching and research institutions in France or abroad, or from public or private research centers.
L'archive ouverte pluridisciplinaire HAL, est destinée au dépôt et à la diffusion de documents scientifiques de niveau recherche, publiés ou non, émanant des établissements d'enseignement et de recherche français ou étrangers, des laboratoires publics ou privés. 
1 Is PCBs concentration variability between and within freshwater fish species explained by their contamination pathways?

3

4 Lopes C. ${ }^{a^{*}}$, Perga M.-E. ${ }^{\text {b }}$, Peretti A. ${ }^{a}$, Roger M.-C. ${ }^{a}$, Persat H. ${ }^{c}$, Babut M. $^{\text {a }}$

$6 \quad{ }^{\text {a }}$ Cemagref, UR MALY, 3 bis Quai Chauveau - CP220, F-69336 LYON, France;

7 b INRA UMR CARRTEL 75 avenue de Corzent, F-74203 Thonon les Bains, France

$8 \quad{ }^{\mathrm{c}}$ UMR 5023 - Laboratoire d'Ecologie des Hydrosystèmes Fluviaux (LEHF), Université

9 Claude Bernard Lyon 1, 69221 Villeurbanne, France.

10

$11{ }^{*}$ To whom correspondence may be addressed:

12 Christelle Lopes

13 Cemagref, UR MALY, 3 bis Quai Chauveau - CP220, F-69336 LYON, France.

14 Tel: +33 (0)4-72-20-87-97 / Fax : +33 (0)4-78-47-78-75

15 E-mail: christelle.lopes@ cemagref.fr 
Abstract

Many chemical, physiological, and trophic factors are known to affect bioaccumulation of polychlorinated biphenyls (PCBs) in biota. Understanding the primary factors affecting fish contamination is critical for predicting and assessing risks to uppertrophic level consumers, including humans. Here we identify PCB contamination pathways that could explain within- and between-species variability in fish concentration levels. Three freshwater river fish species (barbel, chub and bream) were sampled at three sites along the Rhone River (France) where fish consumption is partially prohibited because of PCB levels exceeding the European health-based benchmark. The trophic position was assessed using an innovative approach based on stable isotope analyses and Bayesian inference, which takes into account both isotope data variability and parameter uncertainty. The effect of foraging habitat on fish contamination was addressed using stable isotope mixing models. The fish trophic position and PCB concentrations were found to be unrelated while the exploitation of sediment detrital carbon as a food source appeared to be a critical factor affecting fish contamination. Fish length, PCB concentration of the sediment, and individual fish foraging habitat (exploitation of detrital versus planktonic carbon sources) explained $80 \%$ of withinand between-species variability observed in PCB concentrations. These results, obtained for species that have overlapping TPs and exploit different carbon sources, reveal that the important factor in fish PCB contamination is not only what fish consume, but also and essentially the feeding location.

Keywords: freshwater river fish, PCB contamination, stable isotopes, mixing model, Bayesian inference, predictive models 


\section{Introduction}

The contamination of aquatic ecosystems by organic pollutants such as polychlorinated biphenyls (PCBs) can result in consumption advisories and bans ${ }^{1}$. In the Rhone River near the city of Lyon, France, PCB levels above the European health-based regulatory benchmark of $8 \mathrm{pg} \mathrm{TEQ}^{2} / \mathrm{g}$ (wet weight) were measured in fish, resulting in a partial ban on fish consumption in 2007. Various studies have concluded that

bioconcentration (i.e., accumulation of a contaminant through direct uptake from water) was the primary mechanism governing contamination of biota (Leblanc, 1995; Kucklick et al., 1996; Campfens and Mackay, 1997; Zaranko et al., 1997; Burreau et al., 2004), while other studies have suggested other mechanisms, such as biomagnification (i.e., an increase in contaminant concentration in the food chain) (Zaranko et al., 1997; Burreau et al., 2004).

Nonetheless, it is commonly accepted that chemical concentrations in organisms tend to increase with each step in the food chain, resulting in the concentration in organisms at the top of food chains to be many times greater than those in organisms at the bottom (Gobas et al., 1999; Walters et al., 2008).

Three types of factors are known to be important in the PCB bioaccumulation process (Borgå et al., 2004): physico-chemical, physiological, and trophic. Physicochemical factors include hydrophobicity, expressed as the $K_{o w}$ value (octanol-water partition coefficient) of each PCB congener, which accounts for their solubility in water as well as in lipids.

Physiological factors include lipid content (due to the PCB lipophilic property), body size (related, via allometry, to the chemical elimination rate because of an altered surface-tovolume ratio), and sex (Johnston et al., 2002). Many studies on PCB concentrations in aquatic organisms consider the influence of lipids by lipid-normalizing the concentration, but this

\footnotetext{
${ }^{1}$ http://www.rhone-mediterranee.eaufrance.fr/usages-et-pressions/pollution_PCB/pcb-arretes-interdiction.php

2 TEQ=toxic equivalent quantity for dioxin, furan and dioxin-like PCBs
} 
practice is being debated (Hebert and Keenleyside, 1995). The effect of sex has been largely debated, with the assumption that the depletion of lipids associated with female spawning decreases accumulation of hydrophobic organic contaminants (Johnston et al., 2002; Borgå et al., 2004; Debruyn et al., 2004). Finally, trophic factors include individual diet preferences, habitat use (effects on bioaccumulation in terms of changes in exposure, both by water and dietary uptake) (Guildford et al., 2008; Walters et al., 2008), the length of the food chain, and thus trophic position (TP), as a consequence of the biomagnification processes at the individual level, as explained above (Gobas et al., 1999). All of these factors are likely to influence both between- and within-species variability in PCB concentrations. These factors have generally been studied independently in statistical models of bioaccumulation, and their relative contributions are less well known. Considering the ecological and economic impacts of fish consumption bans and advisories in riverine ecosystems, understanding the relative importance of the primary factors influencing bioaccumulation of PCBs in fish is critical for predicting and assessing risks to upper-trophic-level consumers, including humans.

For many years, stable isotope analysis (SIA) has been widely used to relate fish contamination and trophic factors, where TP is estimated deterministically from stable nitrogen isotopes (Post, 2002) and ultimate carbon sources from stable carbon isotopes (Vander Zanden and Rasmussen, 1996; Mazak et al., 1997; Kidd et al., 1998). Isotope mixing models have also been developed to quantify the respective contribution of a few sources (prey) to fish diet (Phillips, 2001; Phillips and Gregg, 2003). Studies combining PCB analysis and SIA have long been used, principally in lakes (Vander Zanden et al., 2000; Tarvainen et al., 2008). Such approaches have made it possible to identify the role played by TP in the variability of contamination between species, but so far have failed to explain inter-individual variability of contamination levels or the role played by habitat. Indeed, these approaches generally suffer from potential sources of uncertainty around the mean estimates of sources, 
such as in trophic fractionation factors, which were not adequately considered from a technical point of view (Jardine et al., 2006). We assume that improving the SIA within such ecotoxicological studies might help address the relationships between interindividual variability in trophic behavior and in PCB contamination levels in fish.

The recent development of stable isotope mixing models based on Bayesian inference (Jackson et al., 2009; Xue et al., 2009; Parnell et al., 2010) is a major advance in SIA since these models take into account data variability and parameter uncertainty (Moore and Semmens, 2008; Xue et al., 2009). The role of diet preferences and habitat partitioning in PCB accumulation has not been adequately considered until now (Hebert and Haffner, 1991; Paterson et al., 2006), although PCB levels differ between habitats because of the chemical properties of the congeners. Indeed, PCB congeners are not all equally hydrophobic and distribute differently among the various aquatic compartments. The use of these Bayesian models in this context should therefore be very useful to determine the role played by characteristic habitats on fish contamination pathways.

Within these models, however, no statistical method has been developed to include data variability and parameter uncertainty in TP estimation. The TP within a single fish species might be highly variable between individuals, inducing differences in PCB bioaccumulation. Addressing the role of inter-individual variability in the TP estimated from SIA on fish PCB contamination therefore requires the development of an adequate statistical method. Using a Bayesian framework to estimate TP, the different biases related to the usual deterministic estimation can be taken into account (Post, 2002).

Hence, the primary goal of this paper is to identify PCB contamination pathways that explain between- and within-species variability in fish PCB concentrations observed in the Rhone River, using an improved SIA approach. The potential role played by feeding habitats was explored applying Bayesian isotope models, while a statistical method based on Bayesian 
111 inference was developed to estimate the fish TP from stable isotope data. The results were

112 then integrated into a statistical predictive model that was developed to establish the

113 probability that the concentration of PCBs in a given fish species exceeds the health-based

114 fish consumption threshold.

\section{Material and Methods} inventoried by catching invertebrates with artificial substrates for an overview of the species

132

\subsection{Study sites}

Fish, invertebrates, and sediments were collected at three sites in France along the Rhone River: (1) Lône de la Morte (MTE), the relative reference site upstream from Lyon and the first contaminated river reach; (2) Grand Large (GDL), a fluvial lake within the contaminated area and close to the city of Lyon; and (3) Ile du Beurre (BRE), a site downstream from Lyon. These sites were chosen for their expected sediment contamination according to the potential contamination sources (a factory specialized in PCB incineration between the two upstream sites and many industrial chemical sites between the two downstream sites). Furthermore, dams border each site and thus limit fish migration to too great a distance.

Sediment cores were collected at each site and radionuclide measurement was used to age the successive layers in each core. The seven iPCB congeners were quantified by the EUROFINS laboratory (Orléans, France) (see Supporting Information [SI] for greater detail).

\subsection{Fish and invertebrate sampling}

Fish and invertebrates were collected at each study site (Table 1) and the fauna were living therein. 
Three large, long-lived freshwater cyprinid species were chosen because (i) they are

134 prone to PCB accumulation over a several-year period; (ii) although they exhibit a relatively

135 similar TP, they have a plastic trophic behavior maximizing trophic variability between

136 individuals (Philippart, 1977); and (iii) they have different diets and they exploit different

137 habitats: the barbel Barbus barbus (Linnaeus, 1758) is a bottom feeder and lives in running

138 rather than deep waters (Baras and Philippart, 1999), the European chub Squalius cephalus

139 (Linnaeus, 1758) is more often found in standing and running waters and feeds in all aquatic

140 compartments (top, middle and bottom waters) (Caffrey et al., 2008) and the bream Abramis

141 brama (Linnaeus, 1758) lives in standing waters and is a bottom and middle feeder (Persson

142 and Brönmark, 2002). Adult specimens were captured with nets or by electro-shocking (Table

143 1). To better control for within-species variability in PCB contamination and diets, only adults

144 were selected in order to limit the effects of age status. Length $(\mathrm{cm})$ and weight $(\mathrm{g})$ were

145 measured, sex was determined, and age was estimated by scalimetry (years). Stomach

146 contents were analyzed in the laboratory.

148 tenuilineatum (Stelfox, 1918) (Table 1), known to be preyed upon by these fish species, were

149 used as primary consumers for the isotopic baselines. They were chosen because they have a

150 known TP in the food web and they are characteristic of distinct carbon sources: large

151 Corbicula feed deeply in sediment (detrital carbon source) (Mouthon, 2003) and Pisidium

152 feed at the sediment surface (autochthonous carbon source) (Mouthon, 2008).

\subsection{Sample analysis}

Invertebrates were starved in the lab for $24 \mathrm{~h}$ to empty their digestive tract of residues

156 frozen at $-20^{\circ} \mathrm{C}$, freeze-dried, weighed again, and finely ground. 
Lipid content (\%) and concentrations of the seven iPCB congeners (ng/g wet weight)

158 were measured by the CARSO-LSEHL group (Lyon, France), according to USEPA standard 1668. Uncertainty of concentrations was evaluated at $20 \%$.

Stable isotope analyses (carbon and nitrogen, expressed as $\delta^{33} C$ and $\delta^{15} N$ ) were performed using the IsoPrime spectrometer (MicroMass, Service Central d'Analyse, Solaize, France) coupled to a EuroEA 3024 analyzer. The uncertainty was $0.3 \%$. For invertebrate baselines, measurements were taken in triplicate. The protocol for stomach content analysis and the fauna inventory is explained in the SI.

\subsection{Stable isotope data analysis}

\subsubsection{Stable isotope mixing models}

We used the SIAR package (Parnell et al., 2010), which incorporates temporal and spatial variability in $\delta^{13} C$ and $\delta^{15} N$ in the stable isotope mixing model (SI, Eq. C1). Using a Bayesian approach, SIAR determines the probability distribution of each respective source contribution to the isotopic profiles of a consumer. For further detail, see Parnell et al. (Parnell et al., 2010). From the two invertebrate baselines (Pisidium being used as a baseline for autochthonous carbon and Corbicula for detrital carbon) (Mouthon, 2003, 2008), SIAR was applied to each fish species and each site to determine the probability distribution of the contribution of detrital carbon $(d C)$ versus autochthonous carbon in supporting the food web. At the individual level, SIAR could not be applied. Nevertheless, a simple stable isotope mixing model with two stable isotopes and two carbon sources can be solved analytically (SI, Eq. C2) in order to determine, for each individual, the percent contribution of detrital carbon $(d C)$ versus that of autochthonous carbon in supporting an individual fish's secondary production. 


\subsubsection{Trophic position estimation}

Post's equation (Post, 2002) with two baselines was used to estimate fish TP (SI, Eq.

183 C3). To take into account $\delta^{5} N$ and $\delta^{13} C$ data variability and parameter uncertainties, we used

184 Bayesian inference (prior information, software, number of iterations, etc. are presented in the

185 SI).

To estimate the individual TP, a bootstrapping method was used by drawing 10,000 parameter sets from the joint posterior distribution obtained for each species from each site.

The samples of the three species were pooled at each site and the mean value of each parameter was used to report TP in the dual graph.

\subsection{Statistical tests and predictive models}

All statistical tests and models developed were performed using the R statistical

A log-linear regression model was developed to explain fish PCB concentration $\left(\sum_{i=1}^{7}{ }_{i} P C B\right.$,

195 shortened $P C B_{f i s h}$ ) on the basis of all available explanatory variables: size, TP, $\delta^{13} C$ or the

196 percentage of detrital carbon exploited $(d C)$, lipid content $(L C)$, sex and site. The site effect

197 was represented by the maximum PCB concentration in the sediment to which fish were

198 exposed during their lifetime ( $\sum_{i=1}^{7} P C B$ in sediment, abbreviated to $P C B_{\text {sed }}$ ), estimated by

199 correlating fish age with sediment dating at each site. Beforehand, the correlation between

200 explanatory variables was tested with a Spearman rank test. Backward stepwise regression

201 was then carried out. 
In the same way, a generalized linear model was developed to explain the probability

$203 p$ that the PCB content of fish tissue exceeds the health-based benchmark using the same explanatory variables.

\section{Results}

\subsection{Contamination data, biometric analysis, stomach content analysis}

\section{and fauna inventory}

In accordance with the study's objective, the results of sediment contamination are only summarized here (see SI for further detail). The three sites appeared to be contaminated differently, the site upstream from Lyon being far less contaminated than the other two

211 (confirming its suitability as a relative reference). During the past 10 years, the maximal PCB concentration measured in the sediment has been $6.26,69.7$ and $55.1 \mathrm{ng} / \mathrm{g}$ dry weight at MTE,

GDL and BRE, respectively (historical trends presented in SI, Fig. A1). sites (ANOVA, $p<0.0001$ ). The site upstream from Lyon was less contaminated than the two downstream sites and chub was consistently the least contaminated fish species (SI, Fig. D1).

217 Fish contamination increased from upstream to downstream. This increase was expressed

218 both as mean PCB concentrations and also as the number of individuals exceeding the health219 risk-based threshold (SI, Fig. D1).

No correlation between PCB concentrations and sex, size, weight, lipid content, $\delta^{13} C$

221 and $\delta^{15} N$ was observed for any species at any site. The lack of a correlation between lipid and 222 PCB concentrations in fish indicates nonequilibrium conditions between individuals and their 223 environment. As a consequence, we did not lipid-normalize PCB concentrations in fish. 
Stomach content analysis, expressed as prey occurrences (SI, Fig. B1) and mean diets

225

226 (SI, Fig. B2), showed differences among sites (suggesting a spatial heterogeneity concerning prey availability) and between species (indicating specific preferences). The chub and barbel diet spectra were broader than the bream spectrum, consistent with their opportunistic behavior. Nevertheless, low individual variability was observed from stomach contents within each species.

Finally, the inventory of the invertebrate fauna at MTE and GDL showed greater diversity at GDL than at MTE (SI, Fig. B3), suggesting a different prey availability between sites.

\subsection{Stable isotope data analysis}

\subsubsection{Stable isotope mixing models}

Using two end members, each representing a feeding habitat, the results of SIAR showed only two patterns among the nine data sets tested (Fig. 1). The first pattern (Fig. 1A), seen for bream and barbel at MTE and BRE, demonstrated that the two carbon sources were exploited equally by the fish. The second pattern (Fig. 1B), seen for chub at all three sites and bream and barbel at GDL, showed that autochthonous carbon sources were preferred to detrital carbon sources.

The application of these mixing models at the individual level showed that the PCB concentration in fish tissue increased with the proportion of carbon from a detrital source (SI, Fig. C1), especially at GDL.

\subsubsection{TP estimation}

Bayesian inference was performed on $\delta^{15} N$ and $\delta^{13} C$ data for each species at each site. Thin posterior distributions for all parameters were obtained (SI, Fig. C2), meaning that each 
data set was sufficiently informative to obtain a good estimation of each parameter. For all species, the most plausible value of the enrichment in $\delta^{15} N$ per trophic level, $\Delta N$, was around $10 \%$ higher at all sites than the mean of 3.4\% currently used (Post, 2002), except for the bream at BRE. The inferred TP showed similar values between species and between sites. Chub had the lowest mean TP at MTE, barbell had the lowest mean TP at GDL, and bream had the lowest mean TP at BRE. The empirical joint posterior distribution showed that TP was negatively correlated with $\Delta N$, as expected (SI, Fig. C3).

The results of SIA (SI, Fig. C4 and C5) and their relation to PCB concentrations (SI, Fig. C1 and C6), are summarized in Fig. 2, illustrating differences not only in trophic levels (along the y-axis), but also in detrital carbon source exploitation (along the x-axis). Overall, it appeared that (i) the exploitation of detrital carbon increased with a decrease in TP; (ii) the difference in TP between species is not highly relevant, while the individual variability in TP could be strong at the same site (up to one trophic level), as in the exploitation of detrital carbon; and (iii) a contamination gradient was particularly marked at GDL according to the xaxis, the most contaminated fish being those exploiting the detrital carbon sources the most (SI, Fig. C1). On the other hand, no contamination gradient was observed according to TP (SI, Fig. C6).

\subsection{Predictive statistical models}

There was no significant difference in fish age between sites and the mean age was estimated at 7.3 years. The maximum PCB concentrations in the sediment to which fish were exposed during their life were 6.26, 69.7 and 55.1 ng/g dry weight at MTE, GDL and BRE, respectively (SI, Fig. A1). No correlation was found between all the explanatory variables.

The backward stepwise log-linear regressions carried out on PCB concentration levels, for all fish species and sites combined, showed no significant effect of sex, lipid content, or 
271 TP. The best model was obtained using only three significant explanatory variables — fish

272 size, percentage of detrital carbon exploited and maximal PCB concentration in the sediment

273 - which together explained $78 \%$ of the total variability:

$$
\begin{aligned}
\log _{10}\left(P C B_{\text {fish }}\right)= & -0.569( \pm 0.167)+0.036( \pm 0.003) * \operatorname{size}+0.779( \pm 0.188) * d C \\
& +0.591( \pm 0.065) * \log _{10}\left(P C B_{\text {sed }}\right)
\end{aligned}
$$

Figure 3 presents the observed versus predicted contamination data obtained from Eq.

1. This representation is useful to evaluate the calibration of the predictive model to the data set and its utility from a risk assessment perspective, even though an independent data set is needed to validate the model's predictive capability. Only a few individuals fall within the quadrant representing an overestimation of the PCB contamination risk (the predicted value exceeds the measured value and exceeds the health-based benchmark). Similarly, only a few samples fall within the quadrant representing an underestimation of risk, i.e., the predicted concentrations are less than the health-based benchmark and the measured concentrations exceed it. The latter case is of greater concern from a risk assessment perspective.

Nevertheless, for all species and all sites, only a few points are concerned (3/113), and for two of the three, the measurement uncertainty interval (PCB concentration uncertainty estimated at $20 \%$ ) overlaps the regulatory threshold.

The best generalized linear model obtained is presented in the SI.

\section{Discussion}

Many studies have highlighted the importance of chemical and biological factors in PCB accumulation by aquatic biota (Borgå et al., 2004). The factors leading to differential accumulation among species have become a major focus of ecotoxicology and environmental chemistry studies in the past few years (Borgå et al., 2004; Guildford et al., 2008; Walters et al., 2008; Gewurtz et al., 2009). There are a number of interacting factors determining withinand between-species variations in PCB concentrations and the importance of these factors 
varies both temporally and spatially. Many studies have shown that size, sex, TP and lipid content are important predictors of PCB concentrations in aquatic organisms (Kidd et al., 1998; Burreau et al., 2004; Missildine et al., 2005).

The use of stable isotope mixing models to describe diet behaviors showed that chub is the only species to predominantly feed on autochthonous carbon sources at the three sites, while bream and barbel showed a similar behavior only at GDL where invertebrate fauna is

301 plentiful and widely available (as observed with the fauna inventory). Combined with observations from gut contents, these results are consistent with the opportunistic behavior of the chub. Moreover, we identified PCB contamination pathways that could explain the individual and between-species variability in PCB contamination levels. High within-species variability was observed for TP and habitat exploitation and PCB contamination levels, whereas gut contents were relatively similar. One reason for these observations might be that only adults, whose diet is assumed to be fixed, were sampled. The variability observed for isotope data and PCB concentrations could stem from different foraging habitats and/or individual life history. Moreover, we observed that sediments are historically more contaminated at GDL than at BRE, while fishes are more contaminated at BRE than at GDL

311 and they specifically exploit more detrital carbon sources at BRE than at GDL. Furthermore, we showed that PCB concentration increases with the exploitation of detrital carbon sources,

313 confirming the results obtained by Berglund et al. (Berglund et al., 2005), who showed that 314 individuals associated with the detrital pathway have higher PCB concentrations than those 315 associated with the algae pathway. All these results confirmed that deposited sediment plays a 316 central role in food-web contamination (Gewurtz et al., 2009), not only its contamination 317 level, but also the ultimate carbon sources supporting the food web. The important factor in 318 fish PCB contamination in the study sites examined was therefore not only what fish 319 consume, but also and particularly the degree of contamination of the food consumed, 
suggesting that spatial gradients of contamination were more important than the type of food

321 consumed and its trophic status.

The present study shows that combining isotopic and contaminant determination

provides an efficient tool to assess the trophic transfer of pollutants such as PCBs within food

webs and to analyze bioaccumulation processes. Nevertheless, this combined use implies that

they have a similar rate of turnover in fish tissues. As mentioned by Perga and Gerdeaux

(Perga and Gerdeaux, 2005), large consumers such as fish have tissue turnover rates ranging

from months to years and their isotopic signature therefore represents their diet over a long

period of time. The turnover of PCBs in tissues is different for each congener, given their

different transformation rates. The congener profiles obtained here were always similar, with

a predominance of congener 153 , known to accumulate at the highest concentrations

331 (Paterson et al., 2007). As a consequence, it is reasonable to think that for the temporal scale considered here, the values of stable isotopes and PCB concentrations used here can be compared.

Lau et al. (Lau et al., 2009) showed that the isotopic signature of consumers and their

335 foods varied with the season and shade conditions in streams, thus affecting the food-web

336 baselines. Nevertheless, employing isotopic values for a single taxon as the baseline seems

337 preferable to using the mean value of primary consumers, because it reduces the high degree

338 of isotopic variability among taxa (Lau et al., 2009). The problem of seasonal and individual

339 variability is considered in the Bayesian framework here by defining uncertainty around

340 baseline isotope values, nitrogen enrichment per trophic level (commonly set at $\Delta N=3.4 \%$ )

341 and TP, and by defining the variability of isotopic values. This new approach demonstrated

342 that: (i) the variability of the $\delta^{15} N$ values is higher than that of the $\delta^{13} C$ values, (ii) the chub

343 has the highest $\delta^{15} N$ variability and the lowest TP, and (iii) $\Delta N$ was estimated to be higher 
344 than $3.4 \%$. As a consequence, neglecting such sources of variability and uncertainties would

345 result in an overall estimation of fish TP for the data studied.

346 Using all available explanatory variables available, we developed a predictive

347 statistical model to explain PCB levels in freshwater river fishes and the probability of those

348 levels exceeding the health-based benchmark. Fish body length, maximum concentration of

349 PCBs in the sediment to which fish were exposed during their lifetime, and fish foraging

350 behavior (and the associated diet) had significant effects, whereas sex, lipid content and TP

351 were not significant predictors for these three fish species that have overlapping TPs and

352 different ultimate carbon sources. It is clear that there are many interacting factors

353 determining within-species variation in PCB concentrations and that the importance of each

354 factor probably varies both temporally and spatially. Nevertheless, the role of sediment

355 contamination in controlling fish contamination has been underlined and most mechanistic

356 food-web models explicitly consider this compartment as a major exposure route (Morrison et

357 al., 1997; Gewurtz et al., 2009). The variability in TP estimated from the present data set is

358 too low to observe a significant relation between TP and PCB concentrations, probably

359 because no piscivorous fish species were considered. The results obtained here are limited to

360 the species considered and cannot be extrapolated to species at a higher trophic level. As a

361 consequence, because of the small differences in TP between the three species studied here

362 and the substantial differences in their feeding areas, the effect of biomagnification processes

363 cannot be entirely excluded. Nevertheless, a correlation between TP and PCB concentrations

364 has rarely been observed between individuals of the same species (Rasmussen et al., 1990).

365 Until now, the fact that uncertainty was neglected in the deterministic estimation of TP could

366 explain why no correlation was found. The Bayesian approach proposed here provides a more

367 robust estimation and thus contributes support to TP's small effect on PCB levels. 
The log-linear model developed here to predict PCB concentration in fish (Eq. 1) can

369 be used in a risk assessment perspective for fish consumption in the sense that there was an

underestimation of risk in only $3 \%$ of cases. Nevertheless, it is clear that the amount of

detrital carbon in the fish diet is not a convenient variable for environmental managers and

that an independent data set is needed to validate the model's predictive capability.

\section{Acknowledgements}

The authors acknowledge Jacques Mouthon (Cemagref, Lyon) for his help on mollusk ecology, Bernard Motte (Cemagref, Lyon) for his contribution to fish and sediment data core sampling, Cédric Giroux (professional fisherman), who contributed to fish sampling, Roger Durand (a local fisherman), who greatly helped select valuable sediment sites and the CONIB (Centre of Nature Observation of Ile du Beurre) staff, especially its former director Georges Grenouillet. This project was funded by the Rhone-Mediterranean and Corsica Water Agency, the Rhone-Alpes Region, the Provence-Alpes-Côte d'Azur Region, and the Compagnie Nationale du Rhône (CNR) in the context of the Rhone ecological restoration plan, and ONEMA (National Office of Water and Aquatic Environments). We thank Linda Northrup for copyediting the text. We are grateful to the anonymous reviewers for their constructive comments.

\section{References}

Babut, M., Miege, C., Villeneuve, B., Abarnou, A., Duchemin, J., Marchand, P., Narbonne, J.F., 2009. Correlations between dioxin-like and indicators PCBs: potential consequences for environmental studies involving fish or sediment. Environmental Pollution 157, 3451-3456. Baras, E., Philippart, J.C., 1999. Adaptive and evolutionary significance of a reproductive thermal threshold in Barbus barbus. Journal of Fish Biology 55, 354-375.

Berglund, O., Nyström, P., Larsson, P., 2005. Persistent organic pollutants in river food webs: influence of trophic position and degree of heterotrophy. Can. J. Fish. Aquat. Sci. 62, 20212032.

Borgå, K., Fisk, A.T., Hoekstra, P.F., Muir, D.C.G., 2004. Biological and chemical factors of importance in the bioaccumulation and trophic transfer of persistent organochlorine 
contaminants in arctic marine food webs. Environmental Toxicology and Chemistry 23, 23672385.

Burreau, S., Zebühr, Y., Broman, D., Ishaq, R., 2004. Biomagnification of polychlorinated biphenyls (PCBs) and polybrominated diphenyl ethers (PBDEs) studied in pike (Esox lucius), perch (Perca fluviatilis) and roach (Rutilus rutilus) from the Baltic Sea. Chemosphere 55, 1043.

Caffrey, J.M., Acevedo, S., Gallagher, K., Britton, R., 2008. Chub (Leuciscus cephalus): a new potentially invasive fish species in Ireland. Aquatic Invasions 3, 201-209.

Campfens, J., Mackay, D., 1997. Fugacity-based model of PCB bioaccumulation in complex aquatic food webs. Environmental Science and Technology 31, 577-583.

Debruyn, A.M.H., Ikonomou, M.G., Gobas, F.A.P.C., 2004. Magnification and toxicity of PCBs, PCDDs, and PCDFs in upriver-migrating pacific salmon. Environmental Science and Technology 38, 6217-6224.

Gewurtz, S.B., Gandhi, N., Christensen, G.N., Evenset, A., Gregor, D., Diamond, M.L., 2009. Use of a food web model to evaluate the factors responsible for high PCB fish concentrations in Lake Ellasj $\tilde{A}_{s}$ en, a high Arctic Lake. Environmental Science and Pollution Research 16, 176-190.

Gobas, F., Wilcockson, J.B., Russell, R.W., Haffner, G.D., 1999. Mechanism of biomagnification in fish under laboratory and field conditions. Environ. Sci. Technol. 33, 133-141.

Guildford, S.J., Muir, D.C.G., Houde, M., Evans, M.S., Kidd, K.A., Whittle, D.M., Drouillard, K., Wang, X., Anderson, M.R., Bronte, C.R., Devault, D.S., Haffner, D., Payne, J., Kling, H.J., 2008. PCB concentrations in lake trout (Salvelinus namaycush) are correlated to habitat use and lake characteristics. Environmental Science and Technology 42, 8239-8244. Hebert, C.E., Haffner, G.D., 1991. Habitat Partitioning and Contaminant Exposure in Cyprinids. Canadian Journal of Fisheries and Aquatic Sciences 48, 261-266.

Hebert, C.E., Keenleyside, K.A., 1995. To normalize or not to normalize ? Fat is the question. Environmental Toxicology and Chemistry 14, 801-807.

Jackson, A.L., Inger, R., Bearhop, S., Parnell, A., 2009. Erroneous behaviour of MixSIR, a recently published Bayesian isotope mixing model: a discussion of Moore \& Semmens (2008). Ecology Letters 12, E1-E5.

Jardine, T.D., Kidd, K.A., Fisk, A.T., 2006. Applications, considerations, and sources of uncertainty when using stable isotope analysis in ecotoxicology. Environmental Science and Technology 40, 7501-7511.

Johnston, T.A., Fisk, A.T., Whittle, D.M., Muir, D.C.G., 2002. Variation in organochlorine bioaccumulation by a predatory fish; gender, geography, and data analysis methods. Environmental Science and Technology 36, 4238-4244.

Kidd, K.A., Schindler, D.W., Hesslein, R.H., Muir, D.C.G., 1998. Effects of trophic position and lipid on organochlorine concentrations in fishes from subarctic lakes in Yukon Territory. Canadian Journal of Fisheries and Aquatic Sciences 55, 869-881.

Kucklick, J.R., Harvey, H.R., Ostrom, P.H., Ostrom, N.E., Baker, J.E., 1996. Organochlorine dynamics in the pelagic food web of Lake Baikal. Environmental Toxicology and Chemistry $15,1388-1400$.

Lau, D.C.P., Leung, K.M.Y., Dudgeon, D., 2009. What does stable isotope analysis reveal about trophic relationships and the relative importance of allochthonous and autochthonous resources in tropical streams? A synthetic study from Hong Kong. Freshwater Biology 54, 127-141.

Leblanc, G.A., 1995. Trophic Level Differences in the Bioconcentration of Chemicals Implications in Assessing Environmental Biomagnification. Environ. Sci. Technol. 29, 154160. 
Mazak, E.J., MacIsaac, H.J., Servos, M.R., Hesslein, R., 1997. Influence of feeding habits on organochlorine contaminant accumulation in waterfowl on the Great Lakes. Ecological Applications 7, 1133-1143.

Missildine, B.R., Peters, R.J., Chin-Leo, G., Houck, D., 2005. Polychlorinated biphenyl concentrations in adult Chinook salmon (Oncorhynchus tshawytscha) returning to coastal and Puget Sound hatcheries of Washington State. Environmental Science and Technology 39, 6944-6951.

Moore, J.W., Semmens, B.X., 2008. Incorporating uncertainty and prior information into stable isotope mixing models. Ecology Letters 11, 470-480.

Morrison, H.A., Gobas, F., Lazar, R., Whittle, D.M., Haffner, G.D., 1997. Development and verification of a benthic/pelagic food web bioaccumulation model for PCB congeners in western Lake Erie. Environ. Sci. Technol. 31, 3267-3273.

Mouthon, J., 2003. Longitudinal and temporal variations of density and size structure of Corbicula fluminea (Bivalvia) populations in the Saone and Rhone rivers (France). Annales De Limnologie-International Journal of Limnology 39, 15-25.

Mouthon, J., 2008. First study of the life cycle of Pisidium tenuilineatum Stelfox, 1918 (Bivalvia, Sphaeriidae). Basteria 72, 45-56.

Parnell, A., Inger, R., Bearhop, S., Jackson, A.L., 2010. Source partitioning Using Stable Isotopes: Coping with Too Much Variation. PLoS ONE 5, e9672.

Paterson, G., Drouillard, K.G., Haffner, G.D., 2006. An evaluation of stable nitrogen isotopes and polychlorinated biphenyls as bioenergetic tracers in aquatic systems. Canadian Journal of Fisheries and Aquatic Sciences 63, 628-641.

Paterson, G., Drouillard, K.G., Haffner, G.D., 2007. PCB elimination by yellow perch (Perca flavescens) during an annual temperature cycle. Environ. Sci. Technol. 41, 824-829.

Perga, M.-E., Gerdeaux, D., 2005. "Are fish what they eat" all year round? Oecologia 144, 598-606.

Persson, A., Brönmark, C., 2002. Foraging capacities and effects of competitive release on ontogenetic diet shift in bream, Abramis brama. Oikos 97, 271-281.

Philippart, J.C., 1977. Contribution à l'hydrobiology de l'Ourthe. Dynamique des populations et production de quatre espèces de poissons cyprinidés: Brabus barbus, Leuciscus cephalus, chondrostoma nasus et leuciscus leusiscus. Institut de zoologie. Université de Liège, Liège, Belgique, p. 225.

Phillips, D.L., 2001. Mixing models in analyses of diet using multiple stable isotopes: A critique. Oecologia 127, 166-170.

Phillips, D.L., Gregg, J.W., 2003. Source partitioning using stable isotopes: coping with too many sources. Oecologia 136, 261-269.

Post, D.M., 2002. Using stable isotopes to estimate trophic position: Models, methods, and assumptions. Ecology 83, 703.

Rasmussen, J.B., Rowan, D.J., Lean, D.R.S., Carey, J.H., 1990. Food chain structure in Ontario lakes determines PCB levels in lake trout (Salvelinus namaycush) and other pelagic fish. Canadian Journal of Fisheries \& Aquatic Sciences 47, 2030-2038.

Tarvainen, M., Vuorio, K., Sarvala, J., 2008. The diet of ruffe Gymnocephalus cernuus (L.) in northern lakes: new insights from stable isotope analyses. Journal of Fish Biology 72, 17201735.

Vander Zanden, M.J., Rasmussen, J.B., 1996. A trophic position model of pelagic food webs: Impact on contaminant bioaccumulation in lake trout. Ecological Monographs 66, 451-477. Vander Zanden, M.J., Shuter, B.J., Lester, N.P., Rasmussen, J.B., 2000. Within- and amongpopulation variation in the trophic position of a pelagic predator, lake trout (Salvelinus namaycush). Canadian Journal of Fisheries and Aquatic Sciences 57, 725-731. 
495 Walters, D.M., Fritz, K.M., Johnson, B.R., Lazorchak, J.M., McCormick, F.H., 2008.

496 Influence of Trophic Position and Spatial Location on Polychlorinated Biphenyl (PCB)

497 Bioaccumulation in a Stream Food Web. Environ. Sci. Technol.

498 Xue, D., Botte, J., De Baets, B., Accoe, F., Nestler, A., Taylor, P., Van Cleemput, O.,

499 Berglund, M., Boeckx, P., 2009. Present limitations and future prospects of stable isotope

500 methods for nitrate source identification in surface- and groundwater. Water Research 43,

$501 \quad 1159-1170$.

502 Zaranko, D.T., Griffiths, R.W., Kaushik, N.K., 1997. Biomagnification of polychlorinated 503 biphenyls through a riverine food web. Environmental Toxicology and Chemistry 16, 1463. 


\section{Figure legends}

506 Fig. 1: Proportion distribution of autochthonous carbon (in black) and detrital carbon (in grey)

507 in fish isotopic profiles determined by stable isotope mixing models. (A) Profile obtained for

508 bream and barbel at the MTE and BRE sites. (B) Profile obtained for chub at the three sites

509 and bream and barbel at site GDL.

510 Fig. 2: Fish trophic position according to the percentage of detrital carbon exploited, with

511 their level of PCB contamination. PCB concentrations are indicated relative to the health-risk

512 benchmark (equal to $\sum_{i=1}^{7}{ }_{i} \mathrm{PCB} \approx 153 \mathrm{ng} / \mathrm{g} \mathrm{ww}$, (Babut et al., 2009))and three times this

513 threshold.

514 Fig. 3: Relationship between predicted (Eq. 1) and observed PCB concentrations (in a $\log _{10}$

515 basis) in breams ( $\square$ ), barbels (O) and chubs $(\triangle)$ at MTE (white), GDL (grey) and BRE (black).

516 Dotted lines correspond to the health-risk benchmark of $153 \mathrm{ng} / \mathrm{g}$ wet weight for the sum of 517 the seven indicator PCBs. 


\section{$518 \quad$ Figures}
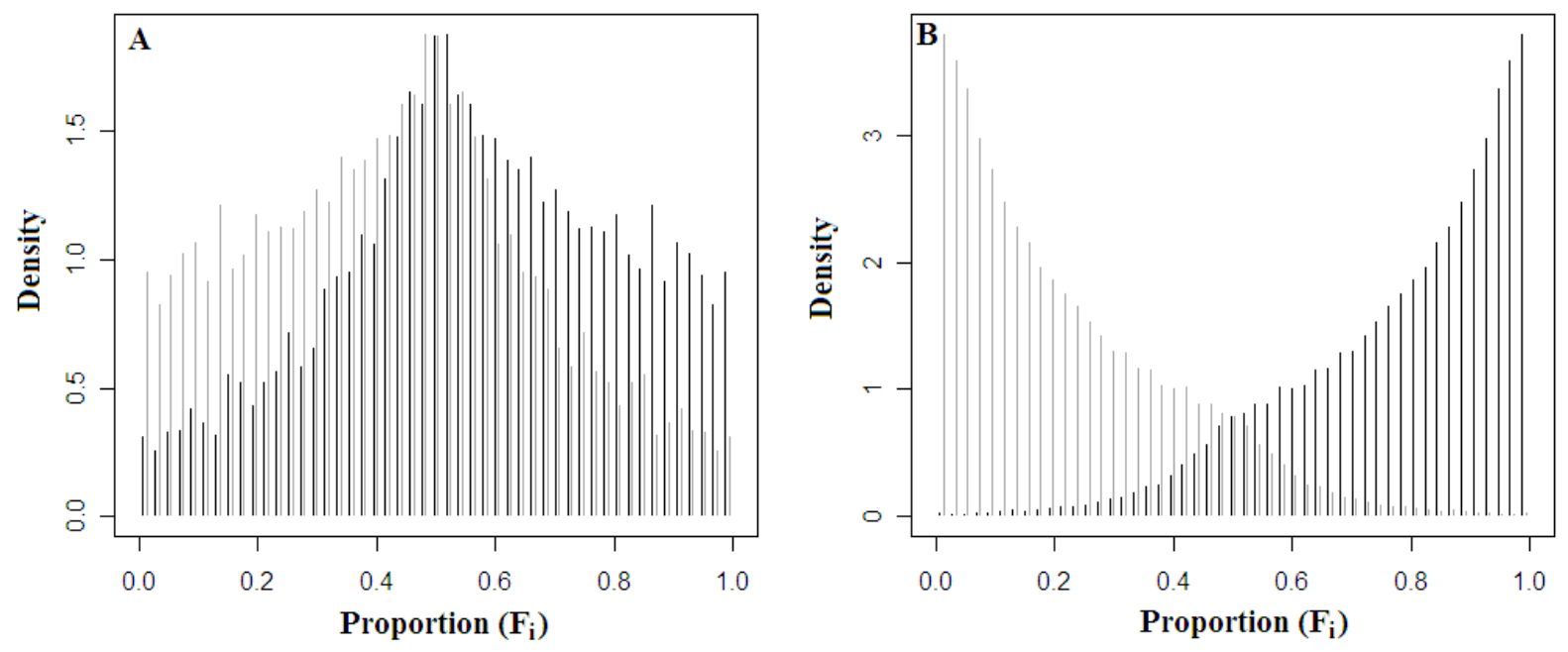

519

Proportion $\left(\mathbf{F}_{\mathrm{i}}\right)$

Fig. 1 
MTE site

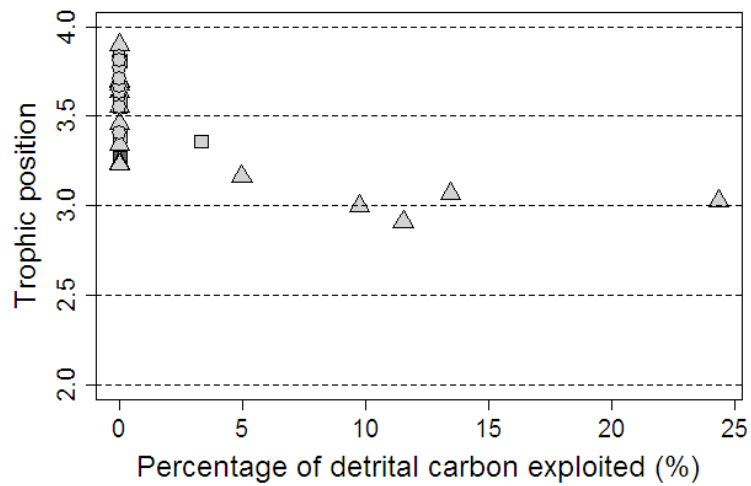

BRE site

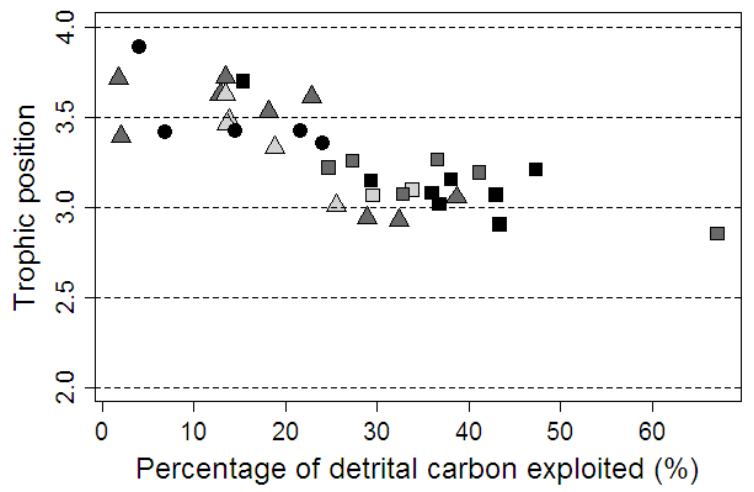

GDL site

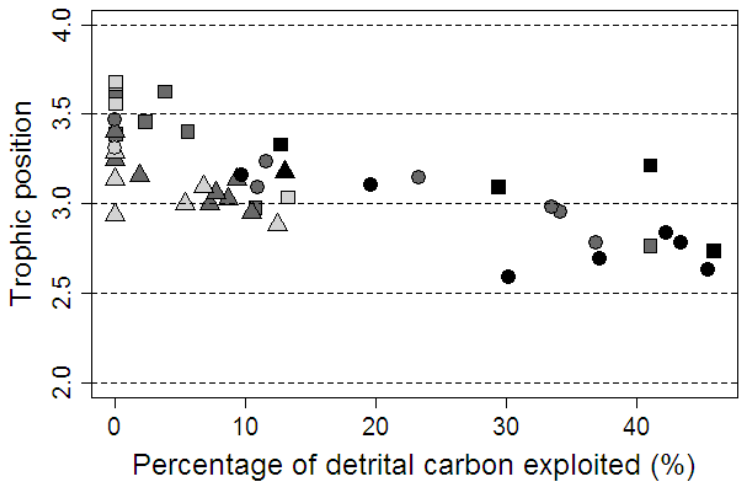

Bream Abramis brama

$\Delta$ Chub Squalius cephalus

- Barbel Barbus barbus

153

500

$\mathrm{PCB}$ concentration (ng/g wet weight)

Fig. 2 


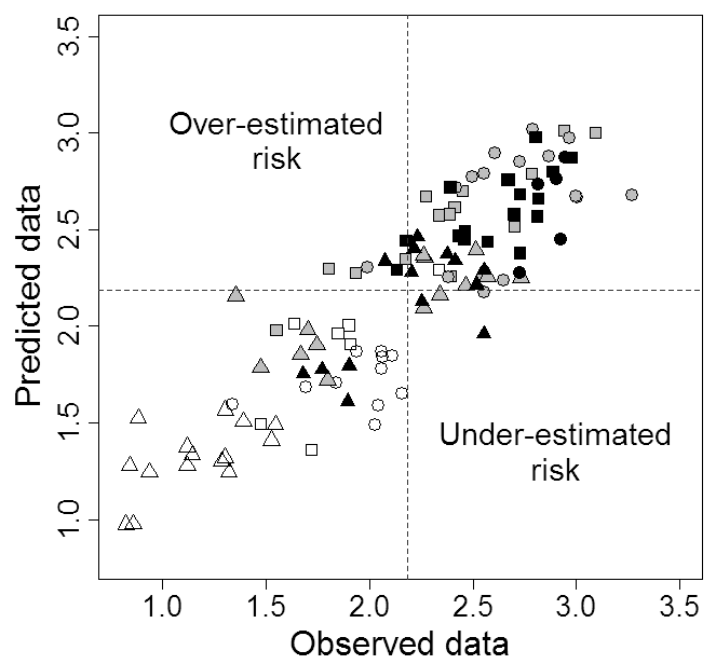

Fig. 3 


\section{Tables}

526 Table 1: Number of fishes and invertebrates collected on each site between August 2008 and

527 January $2009(\mathrm{~N})$, with the distinction between females $(\stackrel{+}{+})$ and males $\left({ }^{\Uparrow}\right)$ for fishes; mean

528 size ( \pm standard deviation); mean weight ( \pm standard deviation); mean age ( \pm standard

529 deviation) and mean lipid content ( \pm standard deviation).

\begin{tabular}{|c|c|c|c|c|c|}
\hline & $\mathrm{N}$ & Size $(\mathrm{cm})$ & Weight (g) & Age (year) & Lipid (\%) \\
\hline \multicolumn{6}{|c|}{ Abramis brama } \\
\hline La Morte & $7\left(3 q+4 \bigcirc^{1}\right)$ & $53.11 \pm 8.18$ & $1636 \pm 775$ & $6.43 \pm 1.51$ & $9.24 \pm 4.76$ \\
\hline Grand-Large & $15\left(9 q+6 \bigcirc^{\lambda}\right)$ & $54.14 \pm 5.78$ & $2025 \pm 695$ & $8.67 \pm 3.96$ & $22.85 \pm 13.93$ \\
\hline Ile du Beurre & $17(10 q+7 \overbrace{}^{\lambda})$ & $52.45 \pm 4.69$ & $2009 \pm 607$ & $5.94 \pm 2.34$ & $28.34 \pm 11.22$ \\
\hline \multicolumn{6}{|c|}{ Squalius cephalus } \\
\hline La Morte & $20\left(13 q+7 \delta^{\lambda}\right)$ & $40.02 \pm 8.76$ & $861 \pm 500$ & $6.3 \pm 1.78$ & $3.2 \pm 1.15$ \\
\hline Grand-Large & $15(6 q+9 \overbrace{}^{\wedge})$ & $44.0 \pm 5.80$ & $1075 \pm 457$ & $5.27 \pm 1.98$ & $7.77 \pm 3.89$ \\
\hline Ile du Beurre & $17(12 q+5 \overbrace{}^{\lambda})$ & $42.58 \pm 7.67$ & $1061 \pm 533$ & $5.82 \pm 2.40$ & $7.62 \pm 3.91$ \\
\hline \multicolumn{6}{|c|}{ Barbus barbus } \\
\hline La Morte & $11\left(11 q+0 \bigcirc^{\lambda}\right)$ & $52.1 \pm 2.92$ & $1215 \pm 117$ & $10 \pm 1$ & $5.85 \pm 2.94$ \\
\hline Grand-Large & $15\left(8 q+7 \delta^{1}\right)$ & $54.7 \pm 6.36$ & $1710 \pm 767$ & $9.4 \pm 2.32$ & $13.62 \pm 6.14$ \\
\hline Ile du Beurre & $5(3 q+2 \hat{\jmath})$ & $56.6 \pm 5.45$ & $1853 \pm 575$ & $9.8 \pm 3.56$ & $17.65 \pm 4.14$ \\
\hline \multicolumn{6}{|l|}{ Invertebrates } \\
\hline & Pisidium & Corbicula & & & \\
\hline La Morte & 140 & 15 & & & \\
\hline Grand-Large & 160 & 13 & & & \\
\hline Ile du Beurre & 130 & 60 & & & \\
\hline
\end{tabular}


Lopes C. ${ }^{a^{*}}$, Perga M.-E. ${ }^{\text {, }}$, Peretti A. ${ }^{a}$, Roger M.-C. ${ }^{a}$, Persat H. ${ }^{c}$, Babut M. $^{\text {a }}$

534

$535{ }^{\mathrm{a}}$ Cemagref, UR MALY, 3 bis Quai Chauveau - CP220, F-69336 LYON, France;

$536{ }^{\mathrm{b}}$ INRA UMR CARRTEL 75 avenue de Corzent, F-74203 Thonon les Bains, France

$537{ }^{\mathrm{c}}$ UMR 5023 - Laboratoire d'Ecologie des Hydrosystèmes Fluviaux (LEHF), Université

538 Claude Bernard Lyon 1, 69221 Villeurbanne, France.

539

540 The supporting Information is divided in five Appendices :

541 - Appendix A : Age sediment dating and contamination

542 - Appendix B : Gut Content Analysis

543 - Appendix C : Stable isotope analysis

544 - Appendix D : Fish contamination

545 - Appendix E : Statistical predictive models 


\section{Appendix A: Age Sediment age dating and contamination}

The results presented here are the subject of a paper in preparation. Only those

548 relevant to this study are summarised here.

Sediment cores were collected at each site with a gravity corer fitted with a $1.2-\mathrm{m}$

550 liner. Radionuclide $\left({ }^{210} \mathrm{~Pb},{ }^{137} \mathrm{Cs}\right)$ measurement was used to age the successive layers in each

core. PCB analysis was performed using high-resolution mass spectrometry (HRGC-HRMS)

by a contract laboratory (EUROFINS in Orléans, France).

Measurements of ${ }^{210} \mathrm{~Pb}$ and ${ }^{137} \mathrm{Cs}$ and correlation with documented hydrosedimentary events were used to estimate a mass accumulation rate (MAR; $\left.\mathrm{g} \cdot \mathrm{cm}^{-2} \cdot \mathrm{yr}^{-1}\right)$ for each interval in each core. At MTE, the estimated sediment MAR is $1.25 \mathrm{~cm}$ per year.At GDLthe MAR is estimated at $1.73 \mathrm{~cm}$ per year. At BRE, the MAR is estimated at $2.5 \mathrm{~cm}$ per year. respective time scale. The concentrations observed during these last 20 years in each site are presented in Fig. A.1.

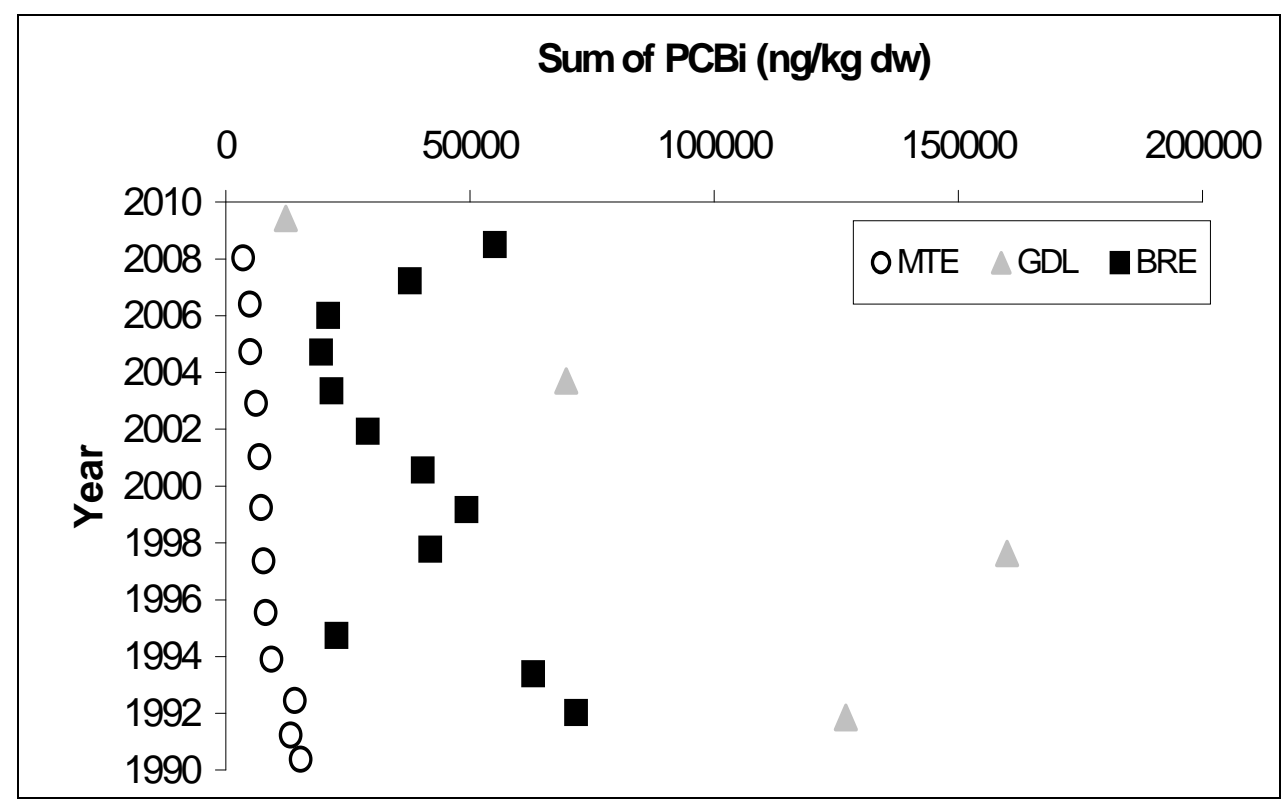

Fig. A1: Historical PCB contamination of sediment in the three study sites. 


\section{Appendix B: Gut Content Analysis and fauna inventory}

\section{3}

564

565

566

567

568

571

572

573

574

575

\section{Stomach content analysis}

Stomach contents were preserved in 5\% formalin before analysis. Prey species were identified and numbered. Fish tissues for PCB analysis were sampled according to the European regulation No. 1883/2006 of the Commission ${ }^{3}$.All species found in the stomach were listed and grouped in seven groups according to their family: (1) dipterans, (2) other aquatic insects, (3) crustaceans, (4) gastropods, (5) bivalves, (6) macrophytes and (7) others. Prey occurrence (expressed as percentage of fish that ate each prey category) were calculated for each fish species for each site, and individual variability and average diet (in number of individuals) were determined. The results for prey occurrence and mean percentage of individuals of each prey class in fish diet are presented in Fig. B1 and B2 respectively.
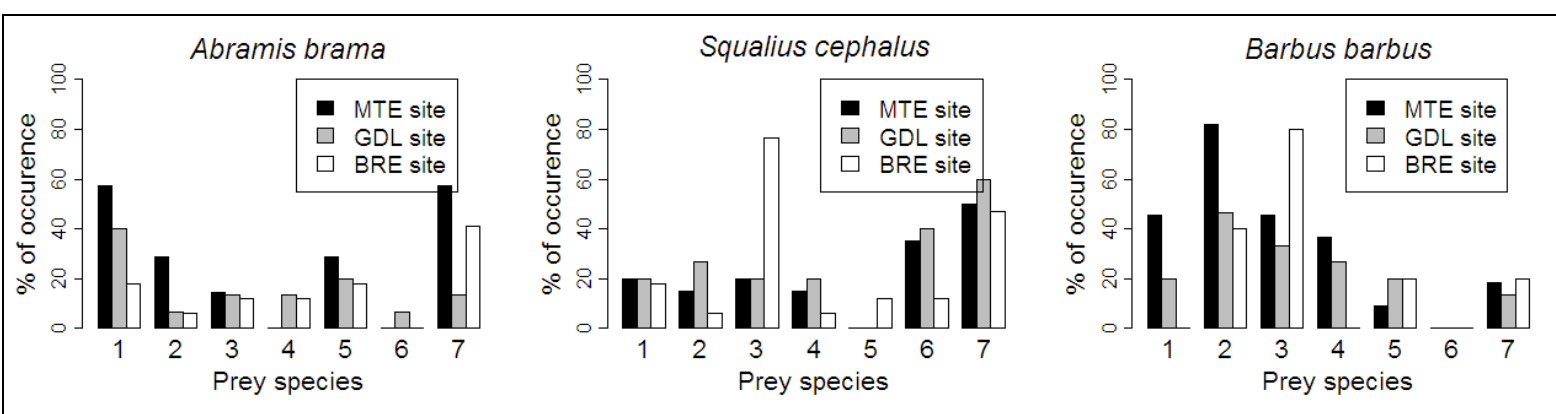

Fig. B1 : Occurrence of each prey category for each fish species at each site.
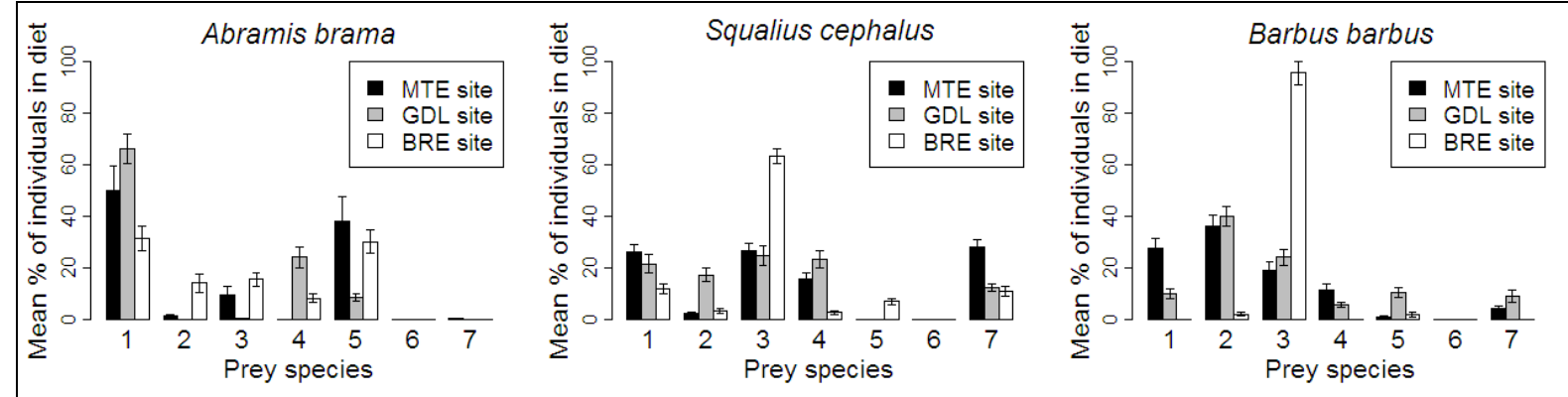

Fig. B2 : Mean percentage of individuals in the diet of each fish species at each site.

${ }^{3}$ E.C. (2006). Commission Regulation (EC) no. 1883/2006 of 19 December 2006 laying down methods of sampling and analysis for the official control of levels of dioxins and dioxin-like PCBs in certain foodstuffs, Official Journal of the European Union. 1883/2006: L 364/32 - 364/43 


\section{$577 \quad$ Fauna inventory}

A fauna inventory was made by catching invertebrates with artificial substrates.

579 Taxonomic determination, abundance and weight were determined in the laboratory. The

580 fauna present in artificial substrates was listed and grouped in 6 groups, the same as the ones

mentioned above for gut contents except that macrophytes are grouped with the last group.

583 for this site is avalaible. The inventory of the invertebrate fauna at MTE (upstream Lyon) and

584 GDL (site closed to Lyon) shows a higher diversity at GDL than at MTE (Figure B3),

585 suggesting a different prey availability between sites.

586

587

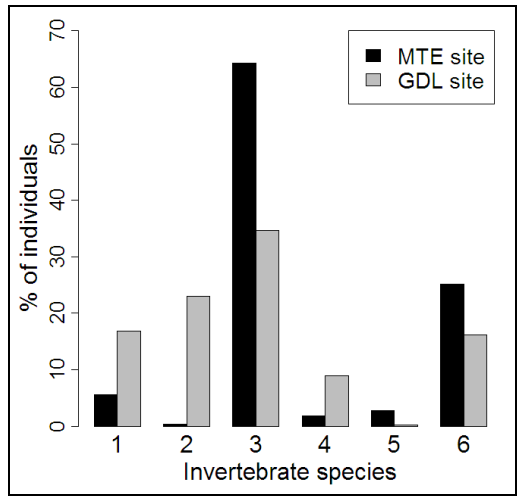

Figure B3: Distribution of invertebrates at MTE and GDL. (1) Dipterans; (2) Other aquatic insects; (3) Crustaceans; (4) Gastropoda; (5) Bivalves; (6) Others. 


\section{Appendix C: Stable isotope analysis}

\section{0} 598 estimated by the model).

600

$601 \quad\left\{\begin{array}{l}\delta^{13} C_{p}=\sum_{i=1}^{2} F_{i} * \delta^{13} C_{i} \\ \delta^{15} N_{p}=\sum_{i=1}^{2} F_{i} * \delta^{15} N_{i} \\ \sum_{i=1}^{2} F_{i}=1\end{array} \Leftrightarrow\left\{\begin{array}{l}F_{1}=\frac{\delta^{13} C_{p}+\delta^{15} N_{p}-\delta^{13} C_{2}-\delta^{15} N_{2}}{\delta^{13} C_{1}+\delta^{15} N_{1}-\delta^{13} C_{2}-\delta^{15} N_{2}} \\ F_{2}=\frac{\delta^{13} C_{1}+\delta^{15} N_{1}-\delta^{13} C_{p}-\delta^{15} N_{p}}{\delta^{13} C_{1}+\delta^{15} N_{1}-\delta^{13} C_{2}-\delta^{15} N_{2}}\end{array}\right.\right.$

At the individual level, a simple stable isotope mixing model with two stable isotopes and two carbon sources can be analytically solved :

$$
\boldsymbol{X}_{c, j}=\sum_{i} \boldsymbol{F}_{i}\left(\boldsymbol{X}_{i, j}+\boldsymbol{C}_{i, j}\right)+\varepsilon_{c, j}
$$

where $X_{c, j}$ is the observed isotope value $j$ of the fish species $c, X_{i, j}$ is the source value $i$ on isotope $j$ (normally distributed), $F_{i}$ is the contribution of the source $i$ (estimated by the model), $C_{i, j}$ is the trophic enrichment factor for isotope $j$ on source $i$ (normally distributed) and $\mathcal{E}_{c, j}$ is the residual error, describing additional inter-observation variance not described by the model (distributed according to a centered normal distribution for which the standard deviation is

At he individual level, a sinple stable isope nixing nowel with two stable isotopes and two (6)

602 The relation between individual PCB contamination of individuals and the ratio between

603 detrital and autochthonous carbon contributions calculated above are presented Fig. C1: 

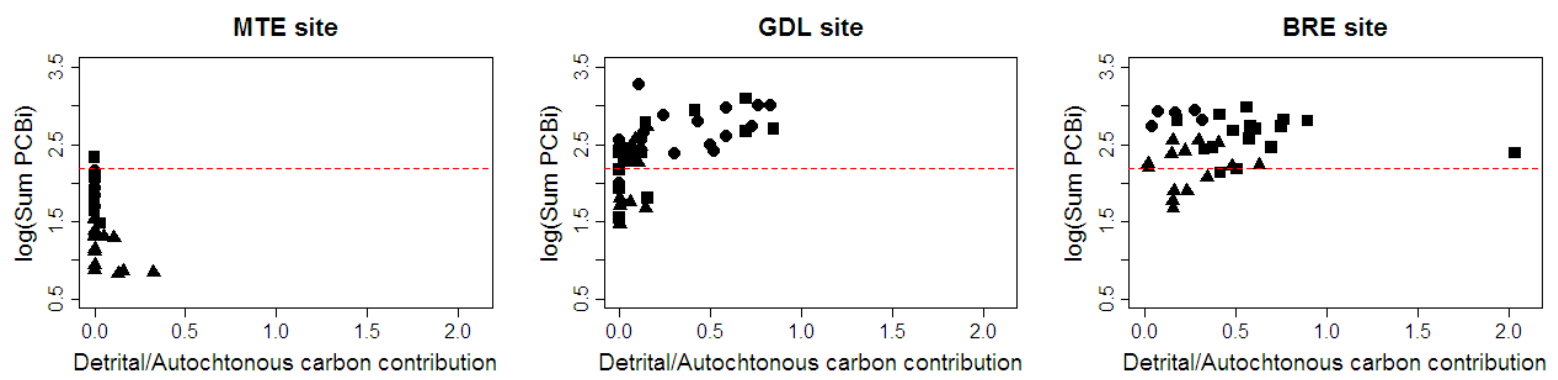

605

Fig. C1: Relation between individual PCB contamination of individuals and the ratio between detrital and autochthonous carbon contributions in fish isotopic profiles obtained with stable

\section{TP estimation}

\section{$\underline{\text { Post's equation }}$}

$$
\mathrm{TP}=\lambda+\frac{\delta^{15} N_{p}-\left(\alpha \delta^{15} N_{\text {base1 }}+(1-\alpha) \delta^{15} N_{\text {base } 2}\right)}{\Delta N} \text { with } \alpha=\frac{\delta^{13} C_{p}-\delta^{13} C_{\text {base } 2}}{\delta^{13} C_{\text {base } 1}-\delta^{13} C_{\text {base } 2}} \text { (Eq. C3) }
$$

where $\lambda$ is the TP of the baselines used (primary consumers, $\lambda=2$ ); $\delta^{15} N_{p}, \delta^{13} C_{p}, \delta^{15} N_{b a s e l}$, $\delta^{13} C_{\text {basel }}, \delta^{15} N_{\text {base } 2}$ and $\delta^{13} C_{\text {base } 2}$ are the values of $\delta^{5} N$ and $\delta^{13} C$ measured in the consumers

616 ultimately derived from the base of the first food web and $\Delta N$ is the enrichment in $\delta^{15} N$ per

617 trophic level (estimated at a mean 3.4\%o) (Post, 2002).

\section{$\underline{\text { Bayesian Inference procedure }}$}

Based on prior distributions assigned to variables and parameters, multiplied by the

620 likelihood of the data, the bayesian approach yields not only the marginal posterior

621 distribution of each parameter, but also an unnormalised joint posterior distribution of the 
622 parameters conditional upon the data (allowing potential structural correlations between the

623 parameters to be controlled).

624 Data variability was incorporated by considering that $\delta^{15} N$ and $\delta^{13} C$ data followed

625 normal distributions with a mean equal to the mean of the observed values and a standard

626 deviation $\sigma_{N}$ and $\sigma_{C}$ estimated by the model. Parameter uncertainties were taken into account

627 by specifying priors: (i) the enrichment in nitrogen per trophic level, $\Delta N$, followed a normal

628 distribution with $3.4 \%$ as the mean and $1.5 \%$ as the standard deviation (Post, 2002); (ii)

629 isotope data for the baselines followed a normal distribution; and (iii) TP followed a uniform

630 distribution between 2 and 5. The TP of the baselines was set at 2 (primary consumers).

631 Bayesian inference was applied via a Monte-Carlo Markov-Chain (MCMC), computed using

632 the WinBugs software (Lunn et al., 2000). The implementation of the procedure needs to

633 define a data file per fish species and per site (with $\delta^{15} N$ and $\delta^{13} C$ values for each fish species

634 and each invertebrate baselines), and a general model data file specifying the parameters to

635 estimate and the priors. For each data set, the inference was made on $6 * 10^{3}$ iterations

636 following $10^{4}$ adaptive iterations, on three independent MCMCs (with three different initial

637 parameter values), resulting in a total of $18^{*} 10^{3}$ parameter sets.

\section{$638 \quad$ Parameter estimates}

639 The posterior distribution obtained by Bayesian inference to estimate each parameter is

640 presented in Fig. C2, for each site. 

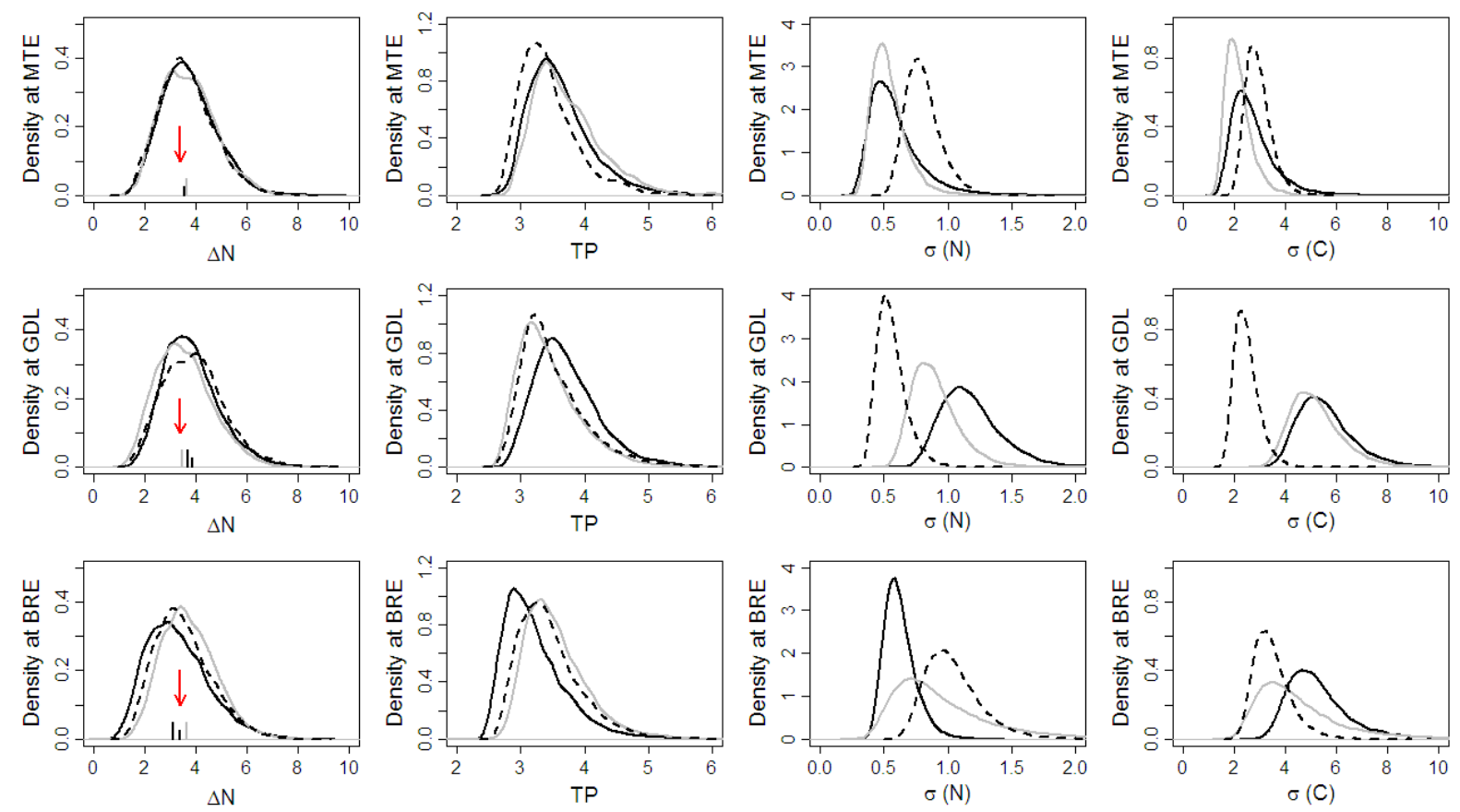

Fig. C2: Posterior distributions obtained for each parameter by Bayesian inference from the bream (-), barbel ( ) and chub (- -) data sets at MTE, GDL and BRE. For $\Delta N$, vertical lines value of 3.4\%o. $\sigma(N)$ and $\sigma(C)$ represent variability around $\delta^{15} N$ and $\delta^{13} C$ data, respectively.

\section{$\underline{\text { Joint posterior distributions }}$}




\section{Squalius cephalus}

656
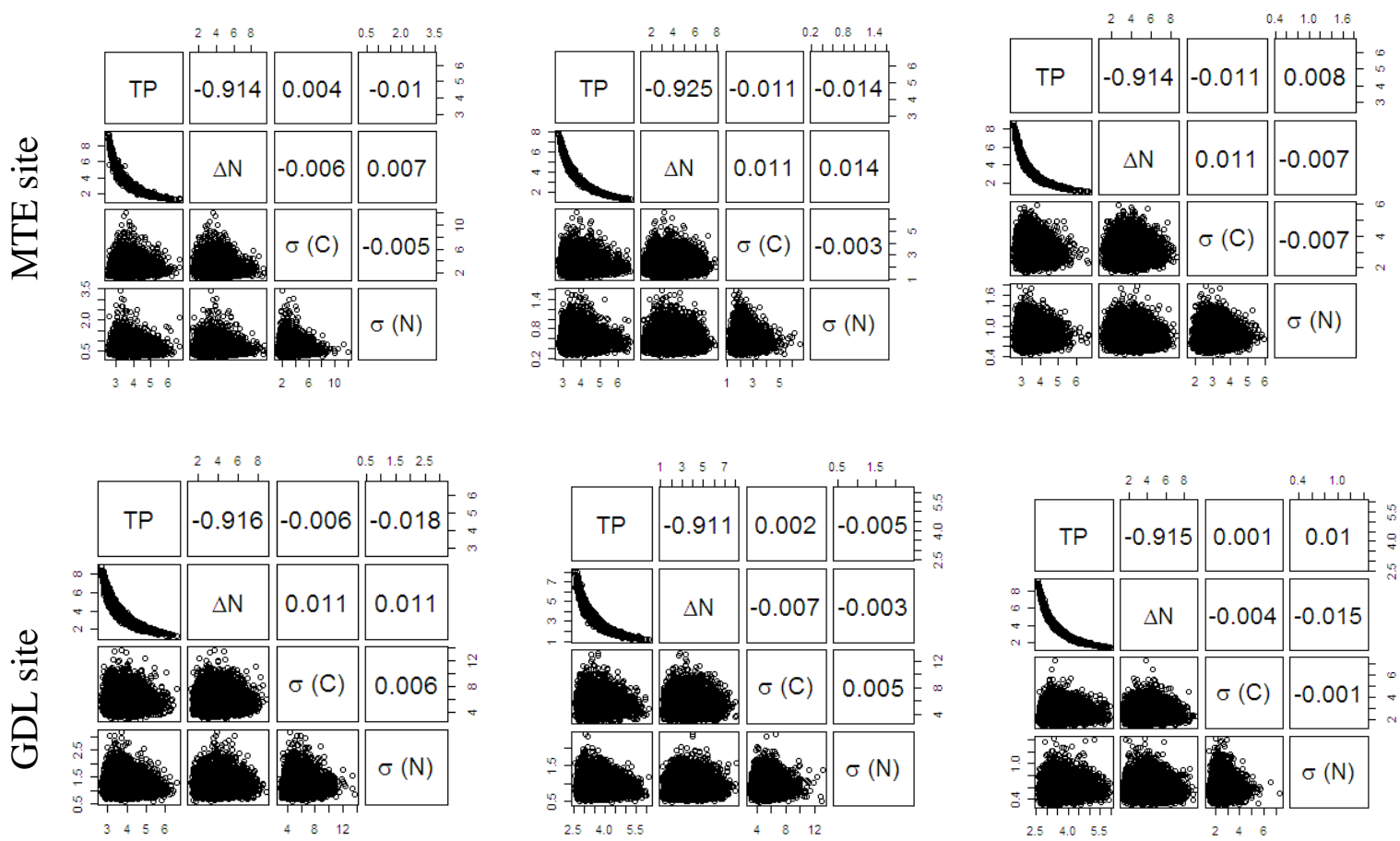

657

658
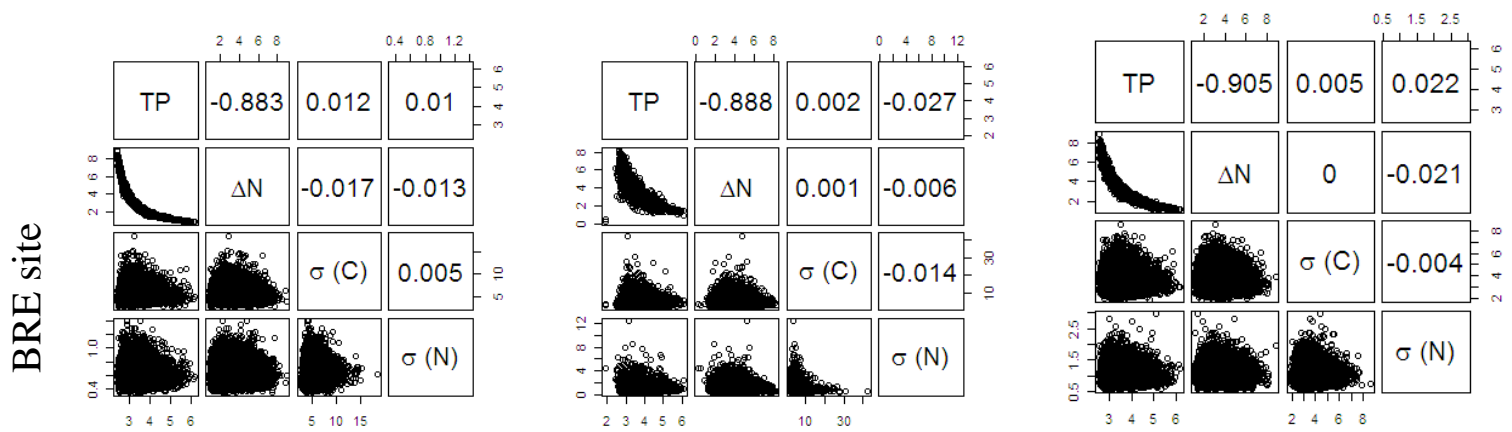

659

Fig. C3: joint posterior probability distribution of the four parameters obtained for each

660 species data set at each site. The projection of MCMC chains in the plane of each pair of parameters are represented in the bottom left of each figure, correlation coefficients between each pair of parameters are represented in the top right of each figure.

\section{Dual graphs}

664 Raw isotopic data $\left(\delta^{15} N\right.$ and $\left.\delta^{13} C\right)$ are presented in Fig. C4 for each site and its associated

665 dual graph with TP in Fig. C5, in link with individual PCB contamination levels. The figure

C6 represents the relation between PCB concentration of individuals and their TP. 
MTE site

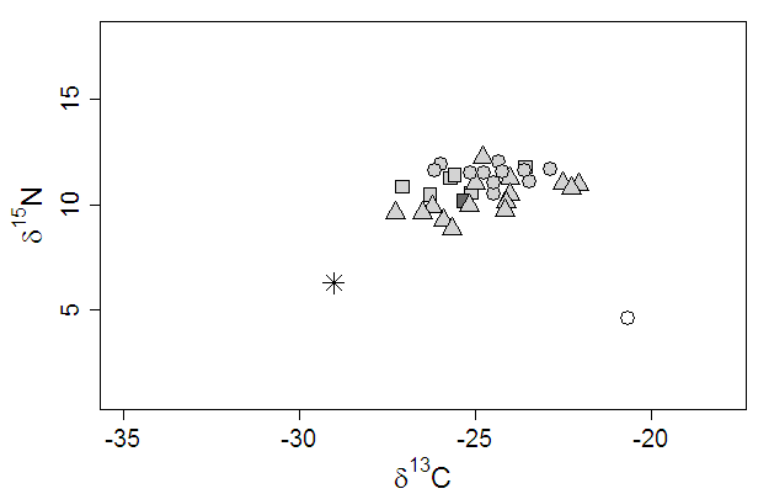

BRE site

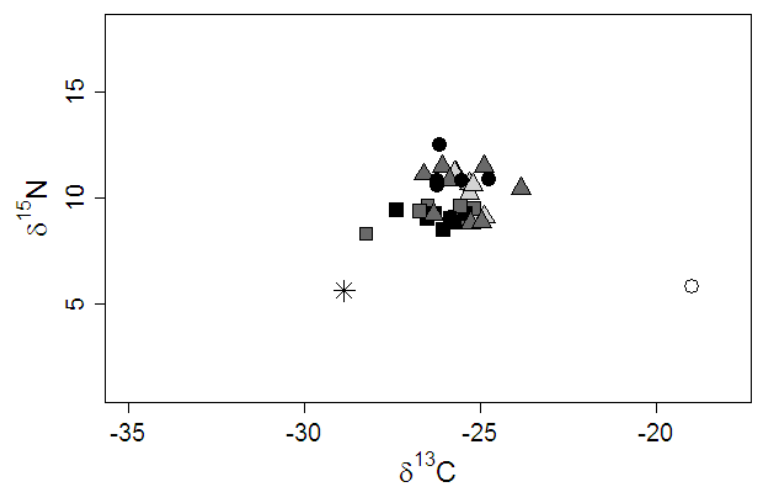

GDL site

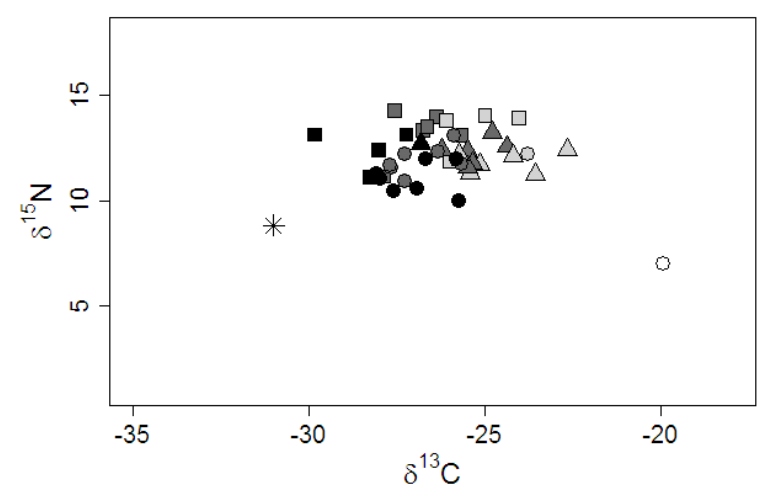



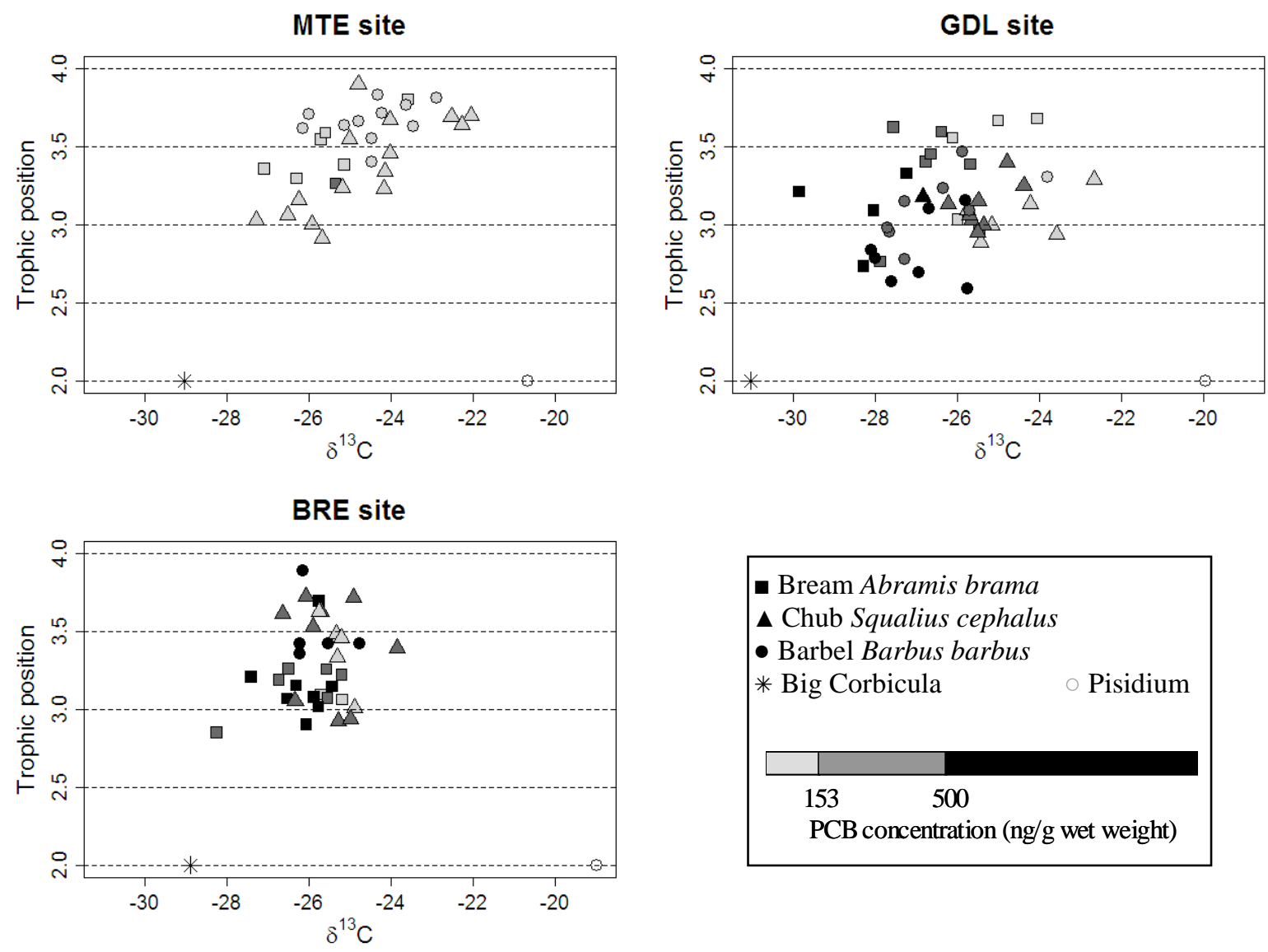

- Bream Abramis brama

$\Delta$ Chub Squalius cephalus

- Barbel Barbus barbus

* Big Corbicula

Pisidium

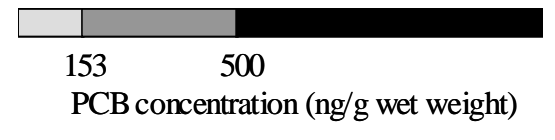

672 Fig. C5: TP versus isotope carbon values in each site, with their level of PCB contamination.

673 PCB concentrations are expressed in relation to the sanitary threshold (corresponding to $\sum_{i=1}^{7}{ }_{i} \mathrm{PCB} \approx 153 \mathrm{ng} / \mathrm{g} \mathrm{ww},($ Babut et al., 2009)) and three times this threshold.
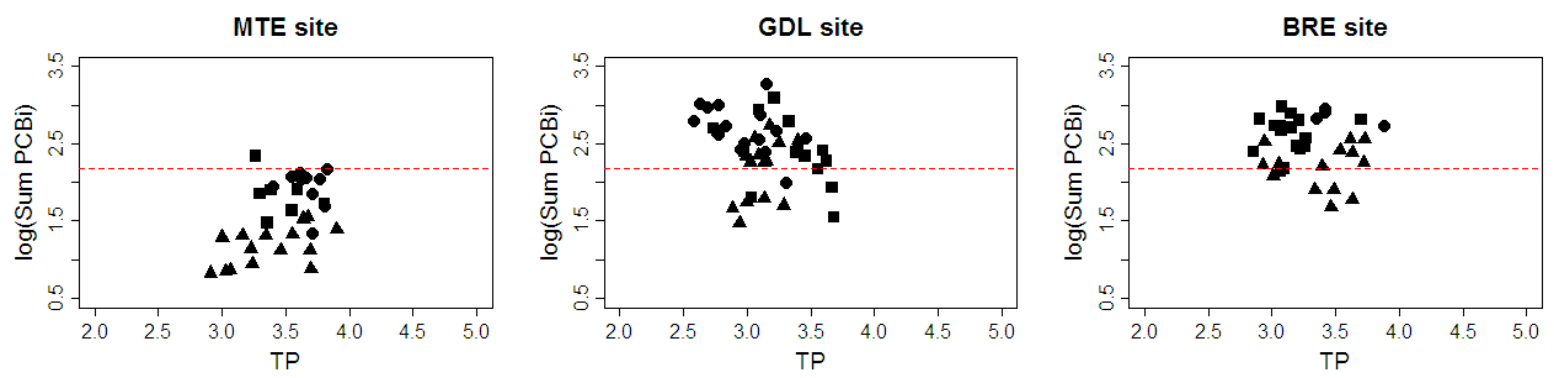

677 Fig. C6: Relation between individual PCB contamination of individuals and their TP for

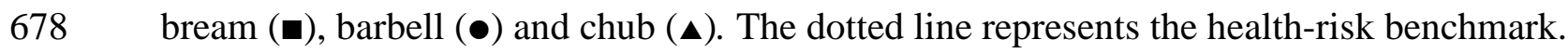




\section{Appendix D: Fish contamination}
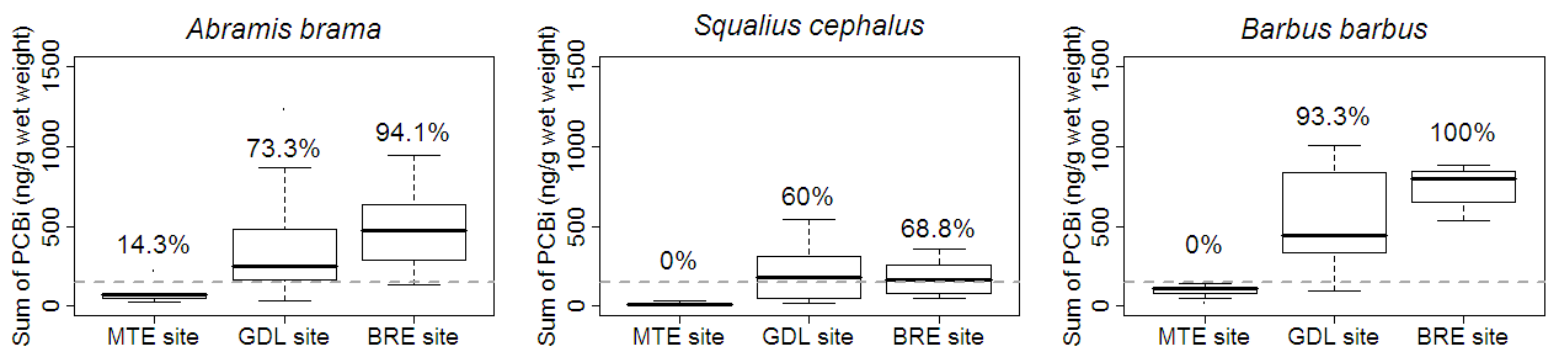

682 Fig. D1: Boxplots of PCB contamination for fish. The dotted line denotes the European

683 health-risk benchmark level of 8 pg TEQ (dioxin, furan and dioxin-like PCBs) / $g$ of fish wet 


\section{Appendix E: Statistical predictive models}

688 before, explaining $70 \%$ of the variation in the probability of exceeding the health-risk

689 benchmark:

690

$\operatorname{logit}(p)=-20.8( \pm 4.65)+0.253( \pm 0.067) *$ size $+6.80( \pm 3.21) * d C+5.01( \pm 1.28) * \log _{10}\left(P C B_{\text {sed }}\right) \quad$ (Eq. E1)

691 